\title{
Intracellular receptors use a common mechanism to interpret signaling information at response elements
}

\author{
D. Barry Starr, ${ }^{1}$ William Matsui, ${ }^{2}$ Jay R. Thomas, ${ }^{3}$ and Keith R. Yamamoto ${ }^{1,4}$ \\ ${ }^{1}$ Departments of Cellular and Molecular Pharmacology, and Biochemistry and Biophysics, PIBS Biochemistry and Molecular \\ Biology Program, University of California San Francisco, San Francisco, California 94143-0450 USA
}

\begin{abstract}
The glucocorticoid receptor (GR) activates transcription in certain glucocorticoid response element (GRE) contexts, and represses or displays no activity in others. We isolated point mutations in one GRE, plfG, at which GR activated transcription under conditions in which the wild-type element was inactive or conferred repression, implying that GREs may carry signals that are interpreted by bound receptors. Consistent with this notion, we identified a mutant rat GR, K461A, which activated transcription in all GRE contexts tested, implying that this residue is important in interpretation of GRE signals. In a yeast screen of $60,000 \mathrm{GR}$ mutants for strong activation from plfG, all 13 mutants isolated contained substitutions at $\mathrm{K} 461$. This lysine residue is highly conserved in the zinc-binding region (ZBR) of the intracellular receptor (IR) superfamily; when it was mutated in MR and RAR $\beta$, the resulting receptors similarly activated transcription at response elements that their wild-type counterparts repressed or were inactive. We suggest that IR response elements serve in part as signaling components, and that a critical lysine residue serves as an allosteric "lock" that restricts IRs to inactive or repressing configurations except in response element contexts that signal their conversion to transcriptional activators. Therefore, mutation of this residue produces altered receptors that activate in many or all response element contexts.
\end{abstract}

[Key Words: Glucocorticoid receptor; transcriptional repression; DNA-binding domain; context-dependent activity; intracellular receptor]

Received January 1, 1996; accepted in revised form March 27, 1996.

Regulation of transcription typically commences with the specific binding of a regulatory protein to a response element close to the target promoter; the regulator also interacts with other regulatory factors, with the transcription machinery and/or chromatin components, therefore modulating the rate of transcription initiation (for review, see Sheldon and Reinberg 1995; Hori and Carey 1994; Tjian and Maniatis 1994). Numerous regulators have been shown to activate transcription in certain cell types and at certain promoters, and to repress in other settings (Meyer et al. 1980; Keleher et al. 1988; Pedersen et al. 1991). Therefore, it is apparent that the precise activity of a regulator can be determined largely by its context-cell type, promoter, response element, and extracellular signals. The mechanisms by which regulators sense and interpret their contexts and thereby display distinct activities in different settings remain to be determined.

The glucocorticoid receptor (GR) is a member of the intracellular receptor (IR) superfamily, which encompasses a large group of transcriptional regulators (Tsai

Present addresses: ${ }^{2}$ Department of Medicine, University of Washington, Seattle, Washington 98195 USA; ${ }^{3}$ Department of Medicine, University of California, La Jolla, California 92093-0652 USA.

${ }^{4}$ Corresponding author. and O'Malley 1994) including the steroid hormone receptors, the retinoid, thyroid and vitamin D receptors, and various "orphan" receptors for which ligands have not been identified. IRs bind DNA through a characteristic zinc binding region (ZBR), a well-conserved structural motif in which two zinc ions each coordinate four cysteine sulfur atoms (Miller et al. 1985; Giguere et al. 1986; Green and Chambon 1987; Rusconi and Yamamoto 1987; Freedman et al. 1988). GR mediates cellspecific effects of glucocorticoids in virtually all cell types, regulating a range of biological processes including intermediary metabolism, immune response, inflammation, development, and cell differentiation (for review, see Ballard 1989; Orth et al. 1992). On binding glucocorticoids, GR associates with specific genomic sites termed glucocorticoid response elements (GREs), from which it can activate or repress transcription. Hence, GR action is strongly determined by its context.

The GR ZBR is multifunctional. First, the ZBR interacts with GREs, notably through sequence-specific DNA binding (for review, see Tsai et al. 1988), and also by associating with nonreceptor protein factors that are themselves bound to certain GREs (Diamond et al. 1990; Jonat et al. 1990; Schule et al. 1990; Yang-Yen et al. 1990; Ray and Prefontaine 1994; Scheinman et al. 1995). In addition, the ZBR forms a strong dimer interface on 
interaction with certain GREs (Tsai et al. 1988; Luisi et al. 1991), and thus mediates highly cooperative DNAdependent dimerization. Most surprisingly, the ZBR somehow inhibits transcriptional activation functions of the GR under conditions, such as strong overexpression, in which the hormone-bound GR is not associated with GREs (Lefstin et al. 1994). Therefore, it appears that the transcriptional regulatory domains of GR are configured only after GRE binding. This raised the interesting possibility that each GRE might act as a specific allosteric signal that directs the regulatory domains to assume conformations that activate, repress, or have no effect upon transcription.

GREs can be divided into at least three functional classes-simple, tethering, and composite (see Fig. 9, left; for review, see Miner et al. 1991). Simple GREs are DNA sequences, typically imperfect palindromes, to which GR binds as a dimer (Tsai and O'Malley 1994) and activates transcription; repression from simple GREs has not been observed. GR is the sole DNA-binding factor necessary for glucocorticoid regulation from simple GREs. In contrast, certain nonreceptor transcriptional regulators are required for GR function at tethering and composite GREs. At tethering GREs, GR binds not to DNA but rather to a nonreceptor transcriptional activator. In this context, GR represses transcription; activation by GR at tethering GREs has not been observed. At composite GREs, GR interacts both with specific DNA sequences and with DNA-bound nonreceptor factors $/ \mathrm{Di}$ amond et al. 1990; Imai et al. 1993; Frenkel et al. 1994; Mittal et al. 1994). Although GR can bind composite elements in the absence of the nonreceptor components, it regulates transcription only in their presence; GR may either activate or repress transcription from such sites, depending on the subunit composition of the nonreceptor factor.

An understanding of the molecular structure of IRs is just beginning to emerge. In the case of the GR, the structures of the ZBR in the absence of DNA and bound to a simple GRE have been determined (Hard et al. 1990; Luisi et al. 1991), but complexes of the ZBR with composite or tethering GREs have not been defined structurally. Moreover, nothing is known of the effects that those interactions may have on transcriptional regulatory structures. It is apparent, however, that the GR uses "context information" from GRE DNA sequences and bound nonreceptor proteins as determinants of whether it will activate or repress transcription. This suggests that GR may assume distinct conformations at different GREs, and that it may contain an allosteric "lock" or "switch" that governs formation of alternative surfaces for activation and repression of transcription.

In this study we sought to test genetically whether GREs serve as part of the signaling machinery that communicates with GR, and whether GR harbors a mechanism for responding differentially to different GRE signals. We began by mutating a composite GRE to test the prediction that alterations in a presumptive signal might switch the transcription response from, for example, repression to activation. We then set out to identify resi- dues in GR responsible for interpreting GRE-associated signaling information. We found that alteration of K461, one of the residues that makes specific base contacts with the simple GRE, gave phenotypes with strong implications for the notion that GR carries a signal-responsive allosteric lock. Using genetic screens and comparisons with other IR family members, we then tested the significance and generality of a role for this residue in this allosteric function.

\section{Results}

Mutations of plf $G$ that result in transcriptional activation by $G R$

GR alone binds to the plfG composite GRE, but fails to elicit a regulatory response, whereas GR activates transcription on binding to a palindromic simple GRE. One explanation for this difference is that the distinct DNA sequences of the two response elements may produce different allosteric effects on GR, which in turn lead to distinct transcriptional readouts. Lefstin et al. (1994) have reported independent evidence that DNA is an allosteric determinant of GR function (see Discussion). A prediction of this model is that certain GRE mutations may alter GR function without altering its DNA affinity. To test this idea, we mutated the plfG composite GRE, a 25-bp sequence associated with the proliferin promoter that binds both GR and members of the APl family of dimeric transcription activators (Mordacq and Linzer 1989; Diamond et al. 1990). GR binds plfG in the absence of APl, but regulates transcription only in the presence of APl, activating if APl consists of c-Jun homodimers, and repressing if AP1 is comprised of c-Jun-c-Fos heterodimers (Diamond et al. 1990; see Fig. 9, below).

We constructed a series of point mutations in plfG and screened them by transient transfections in murine F9 cells (which lack endogenous GR or AP1 activity) for mutants that acquired simple GRE activity, that is, activation by GR in the absence of AP1. Two mutations, termed TG7 and AC17 (Fig. 1a), which had no effect on the affinity of GR for plfG (W. Matsui, unpubl.), produced a switch to the simple GRE phenotype (Fig. 1b). Moreover, both TG7 (data not shown) and AC17 (Fig. 1c) also mediated strongly elevated activation by GR in the presence of c-Jun homodimers, as well as modest activation of transcription by GR in the presence of c-Junc-Fos heterodimers, a condition in which GR represses from wild-type plfG (Fig. 1c). These results support the hypothesis that specific GRE sequences can act as determinants of GR activity.

\section{Mutations of $G R$ residues that contact bases in a simple GRE}

The phenotypes of the TG7 and AC17 mutants imply that GR can sense and interpret differentially different DNA sequences, presumably through its DNA binding surface. To provide a frame of reference for identifying this putative sequence interpretation activity, we began by altering a known surface. We mutated individually to alanine the three GR residues that make specific side- 


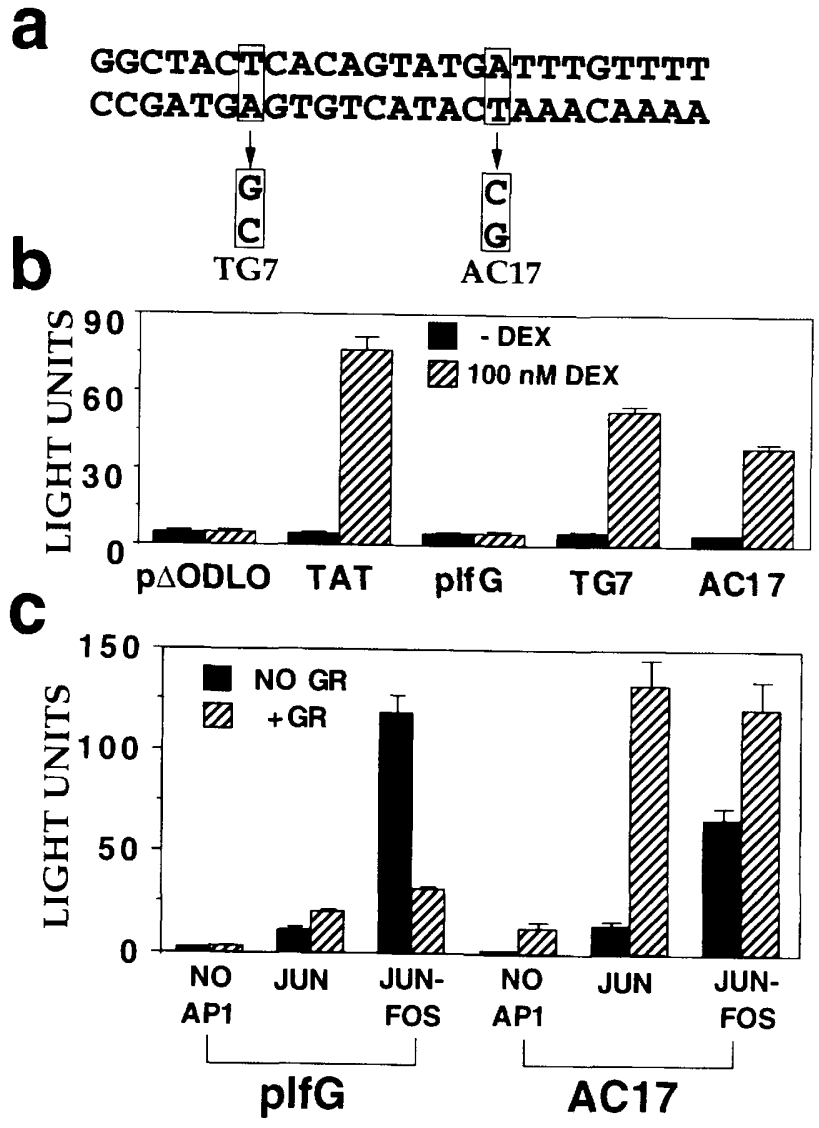

Figure 1. The effect of two mutations in plfG, TG7, and AC17, on GR-mediated transcriptional regulation in transiently transfected mouse F9 cells. $(a)$ Sequence of the proliferin composite GRE, plfG (Mordacq and Linzer 1989; Diamond et al. 1990), and positions of the TG7 and AC17 mutations. $(b)$ Effect of wildtype GR on expression from the simple GRE, TAT, plfG, plfGTG7, and plfGACl7 in the absence or presence of $0.1 \mu \mathrm{M}$ dexamethasone. (c) Effect of the AC17 mutation on the activity of GR in the absence of AP1, and in the presence of either c-Jun or c-Jun and c-Fos. For this and subsequent transfection assays, luciferase or CAT activity was normalized to the activity of a $\beta$-galactosidase expression plasmid as a control for transfection efficiency. Data are the average of two transfections carried out in triplicate; error bars represent standard error of the mean.

chain contacts with DNA bases at the simple GRE s3 (Luisi et al. 1991). We first tested the effects of these mutations, K461A, V462A, and R466A, on the activity of GR from a simple GRE reporter, GTCO, in murine F9 cells, which lack endogenous GR or APl activity. As expected, each mutant displayed decreased transcription activation from GTCO (Fig. 2a): V462A was compromised only modestly and R466A was virtually inactive, whereas K461A was somewhat reduced in activity but significantly more active than predicted either by its central role in DNA binding (Luisi et al. 1991) or by its decreased DNA-binding affinity (see Fig. 3a).

\section{Mutant K461 A activates transcription in all contexts}

We next assessed the effects of these mutations on GR activity at plfG composite GRE in transient transfection assays using a plfG $\mathrm{G}_{3} \mathrm{Luc}$ reporter in $\mathrm{F} 9$ cells. The mutant V462A behaved similarly to wild-type GR under all conditions tested, likely reflecting the conservative nature of the amino-acid substitution. Thus, wild-type and V462A had no effect on luciferase expression in the absence of cotransfected AP1, activated transcription $\sim 10$ fold in the presence of c-Jun (Fig. 2b, inset), and repressed transcription 6- and 12-fold, respectively, in the presence of c-Jun and c-Fos (Fig. 2c). Interestingly, the mutant R466A was also indistinguishable from wild-type GR in

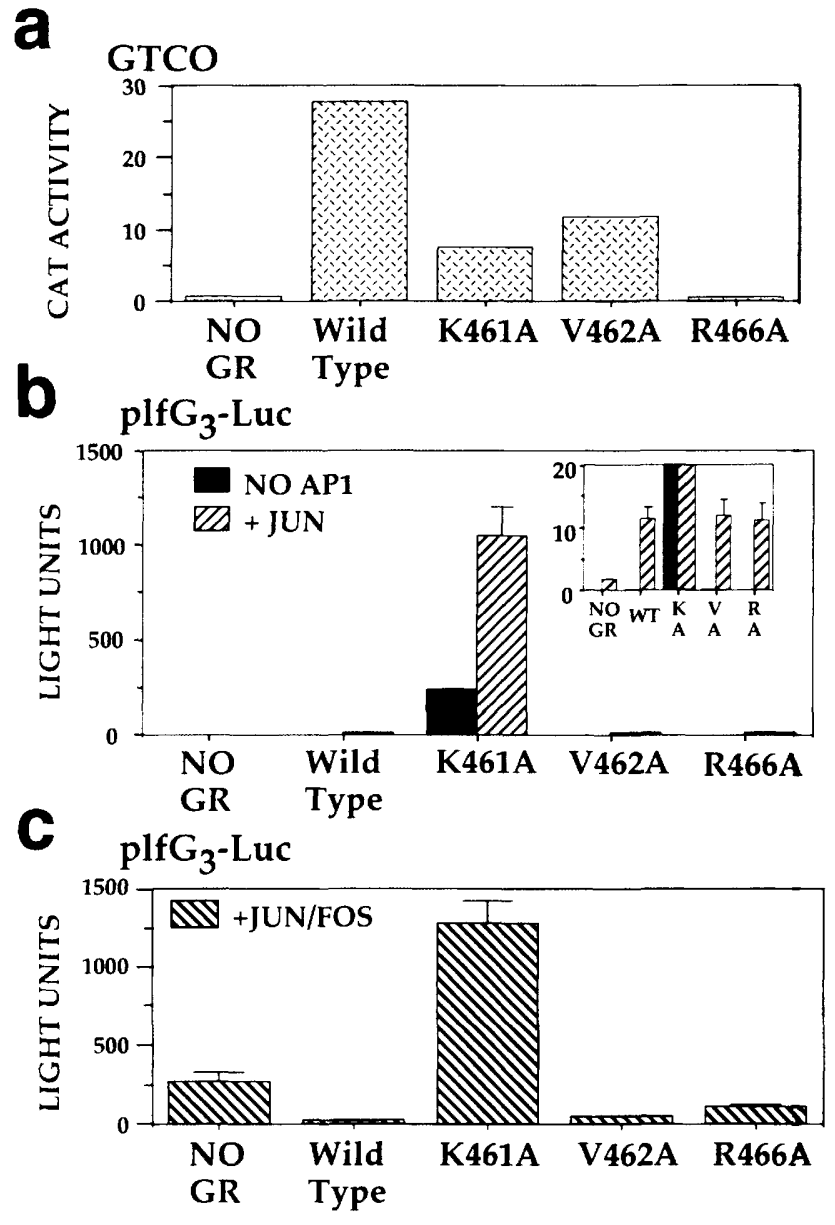

Figure 2. The effect of alanine substitutions at K461, V462, and R466 on the activity of rat GR from simple and composite GREs in transiently transfected mouse F9 cells. $|a|$ Effect of wild-type, K461A, V462A, and R466A GR on expression from the simple GRE reporter GTCO, in the presence of $0.1 \mu \mathrm{M}$ dexamethasone. Shown is a representative transfection; essentially similar data were obtained in three experiments. $(b)$ Effect of wild-type, K461A, V462A, and R466A GR on expression from the reporter plfG $_{3}$ Luc in the absence or presence of c-Jun. (Inset) Data from 0-20 relative light units on a different scale, allowing comparison of activation by wild-type, V462A, and R466A in the presence of c-Jun. (WT) Wild-type GR; (KA) K461A; (VA) V462A; (RA) R466A. (c) Effect of wild-type, K461A, V462A, and R466A GR on expression from the reporter plfG G $_{3}$ Luc in the presence of c-Jun and c-Fos, in the presence of $0.1 \mu \mathrm{M}$ dexamethasone. Data are the average of two transfections carried out in triplicate; error bars represent standard error of the mean. 

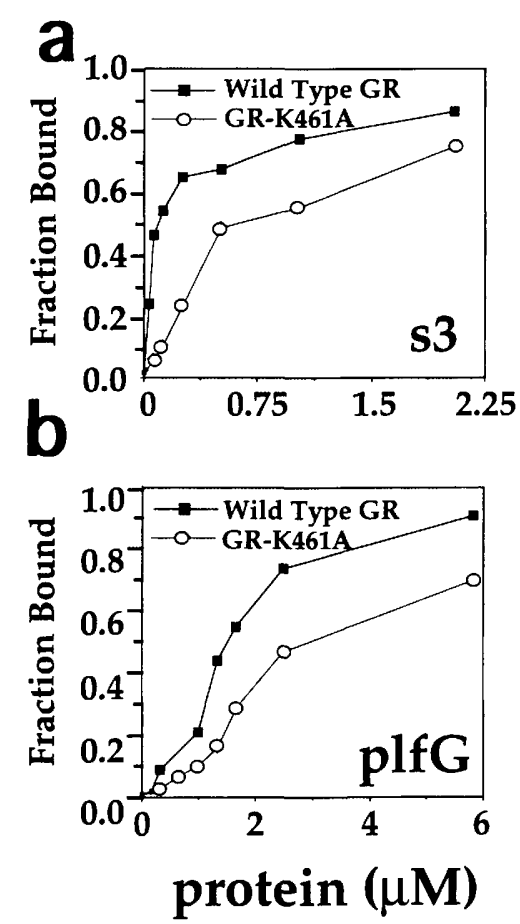

Figure 3. Binding of wild-type GR and $\mathrm{K} 461 \mathrm{~A}$ to the simple GRE, s3, and the composite GRE, plfG. Increasing amounts of EX525-HMK derivatives of wild-type GR or K461A overexpressed in, and purified from, the BL21/DE3 strain of Escherichia coli were incubated with either s $3\langle a\rangle$ - or plfG $\langle b|$ - containing oligonucleotides, and electrophoresed in a $4 \%$ polyacrylamide gel as described in Materials and methods. Complex formation was quantitated by excising the regions corresponding to complexed and free DNA and measuring the radioactivity in a liquid scintillation counter.

the absence or presence of $c$-Jun (Fig. 2b, inset), but it was compromised somewhat in repression activity, decreasing reporter expression only about two-fold in the presence of c-Jun and c-Fos (Fig. 2c). This may indicate that R466 has a selective role in transcription repression but not activation from plfG.

The behavior of mutant $\mathrm{K} 461 \mathrm{~A}$ at plfG was surprising. In the absence of cotransfected AP1, K461A increased luciferase activity $\sim 200$-fold from the plf $_{3}$ Luc reporter and, in the presence of c-Jun, transcription activation was $\sim 100$-fold stronger than that seen with wild-type GR (Fig. 2b). The most remarkable finding was in the presence of c-Jun and c-Fos, where K461 A not only failed to repress transcription, but activated it an additional three- to fourfold (Fig. 2c). Gel mobility shift (Fig. 3b) and fluorescence anisotropy (data not shown) assays showed that these effects of K461A do not reflect an increased affinity for plfG; K461A binds to plfG slightly more weakly than wild-type GR. We have observed the striking behavior of $\mathrm{K} 461 \mathrm{~A}$ at $\mathrm{plfG}$ over a broad range of transfected DNA levels $(0.01-6.0 \mu \mathrm{g})$ in various cellular contexts, including established lines such as CV-1 (see below) and HeLa (data not shown), primary cultures of normal dermal fibroblasts and fibrosarcoma cells (Vivanco et al. 1995), and Saccharomyces cerevisiae (see Fig. 7a, below). Thus, the behavior of the K461A mutant mimics the behavior of wild-type GR at the TG7 and AC17 mutations of plfG, suggesting that K461 may be part of a molecular device by which GR senses and interprets specific DNA sequence information.

We next tested the activity of K461A at a tethering GRE where GR is recruited by protein-protein rather than protein-DNA interactions. We used a site near the collagenase promoter (Jonat et al. 1990; Schule et al. 1990; Yang-Yen et al. 1990), here denoted as colA, at which AP1 but not GR binds to DNA. At this element, wild-type GR associates with the bound API protein and represses the APl-activated transcription (Konig et al. 1992). We cotransfected into F9 cells a colA-Luc reporter plasmid together with wild-type GR or K461A expression plasmids. Neither affected reporter expression in the absence of cotransfected AP1 (Fig. 4), consistent with the absence of a binding site for GR at colA. In the presence of c-Jun and c-Fos, wild-type GR repressed reporter expression approximately fivefold, whereas $\mathrm{K} 461 \mathrm{~A}$ activated expression about four- to fivefold (Fig. 4). This result is reminiscent of previous reports that mutant K461G activates transcription from the IL-6 (Ray et al. 1991) and collagenase promoters (Lucibello et al. 1990; Yang-Yen et al. 1990).

Taken together, our findings imply that K461 may comprise a crucial part of a switch that constrains GR in an inactive or repressing conformation until it associates with a GRE target, either DNA, DNA and protein, or protein alone. On GRE binding, this switch then interprets the GRE signaling information and determines whether GR will activate or repress transcription. In this view, the $\mathrm{K} 461 \mathrm{~A}$ mutation results in a protein that mis-

\section{colA-Luc}

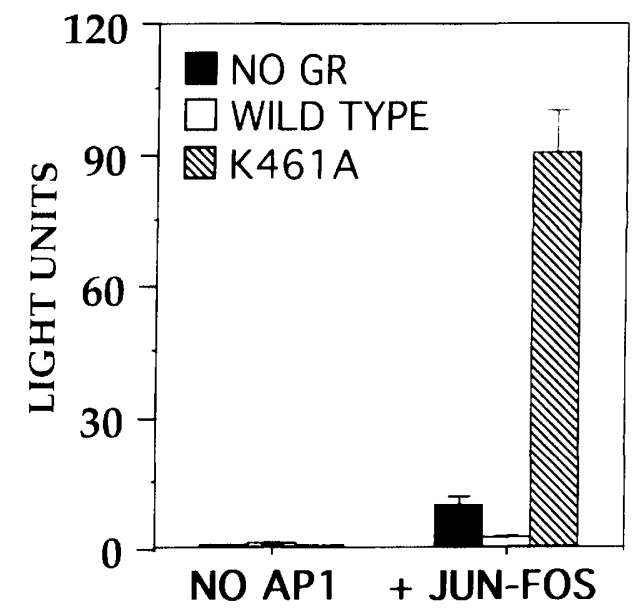

Figure 4. The effect of the K461A mutation on GR activity from the colA tethering GRE. Expression from the colA-Luc reporter was assayed in the presence of $0.1 \mu \mathrm{M}$ dexamethasone in transiently transfected mouse F9 cells as described in Materials and methods. Data are the average of two transfections carried out in triplicate; error bars represent standard error of the mean. 
interprets repression signals such that it now activates in all contexts examined.

\section{$G R$ regions required for activation by $K 461 A$ from plfG}

To characterize further the K461A phenotype, we tested whether domains of GR required for activation from a simple GRE were necessary and sufficient for K461Amediated transcription activation from plfG. The 795amino-acid rat GR can be divided into three broad regions (Fig. 5a): (1) region enh2 (amino acids 107-318; Godowski et al. 1988; Hollenberg and Evans 1988), which is required for activation in certain contexts, contributes partial activity in others, and is essential for repression (Pearce and Yamamoto 1993); (2) the ZBR, which includes DNA binding (Giguere et al. 1986; Godowski et al. 1987; Freedman et al. 1988), DNA-induced dimerization (Tsai et al. 1988; Luisi et al. 1991), and nuclear localization functions (Picard and Yamamoto 1987); and (3) the carboxy-terminal region, which includes signaling functions such as hormone (Godowski et al. 1987; Rusconi and Yamamoto 1987) and molecular chaperone (Howard and Distelhorst 1988; Pratt et al. 1988; Howard et al. 1990; Dalman et al. 1991) binding, as well as a transcription activation domain that functions in some contexts but not in others (Godowski et al. 1988; Hollenberg and Evans 1988|. The five deletion mutants diagramed in Fig. 5a, each containing either the wild-type or the K461A ZBR, were tested for activity in $\mathrm{F} 9$ cells on composite $\left(\mathrm{plfG}_{3} \mathrm{CAT}\right)$ and simple (TAT-CAT) GRE reporters. The deletion constructs included 407C, which lacks amino acids 1-406; N525, which lacks amino acids 526-795; 407-525, which corresponds to the ZBR; GR( $\Delta 107-318)$, which lacks enh2; and EX525, in which enh2 is fused directly to the ZBR.
We found that equivalent deletion derivatives of K461A and wild-type GR evoked similar activities from the simple GRE reporter TAT-CAT in F9 cells (Fig. 5b; Hollenberg and Evans 1988). Thus, K461 A and wild-type activities were reduced only about twofold by deletions that removed either of the two transcription activation domains (Fig. 5b). Deletion of both the amino and carboxyl termini, yielding 407-525, abrogated transcription activation both by the wild-type and the $\mathrm{K} 461 \mathrm{~A}$ versions (Fig. 5b), showing that the K461 A mutation does not fortuitously create an activation domain within the ZBR. We conclude that at this level of resolution, wild-type and K461A GR use similar domains for transcription activation from a simple GRE.

In parallel with these findings, transcription activation by $\mathrm{K} 461 \mathrm{~A}$ from the composite element $\mathrm{plfG}_{3}$ in the absence of AP1 was reduced by at most twofold by deletion of the amino terminus $(407 \mathrm{C})$ or enh2 ( $\Delta 107-318)$, and was abolished with the 407-525 version of K461 A (Fig. $5 \mathrm{c}$. In contrast, whereas deletion of the carboxyl terminus resulted in a twofold decrease in transcription activation with TAT-CAT /compare full length, N525, and EX525; Fig. 5b), it produced a fourfold increase in transcription activation from plfG $_{3} \mathrm{CAT}$ in the absence of AP1 (compare full length, N525, and EX525; Fig. 5c). As expected, equivalent carboxy-terminal truncated versions of wild-type GR failed to activate transcription from plfG ${ }_{3}$ CAT in the absence of AP1 (data not shown). Therefore, carboxy-terminal deletions of K461A have different consequences for activation from plfG ${ }_{3} \mathrm{CAT}$ in the absence of AP1 and from TAT-CAT, increasing activation from the composite element and decreasing it from the simple element; the nature of this distinction has not been investigated.

The relative activities of the various $\mathrm{K} 461 \mathrm{~A}$ deletion
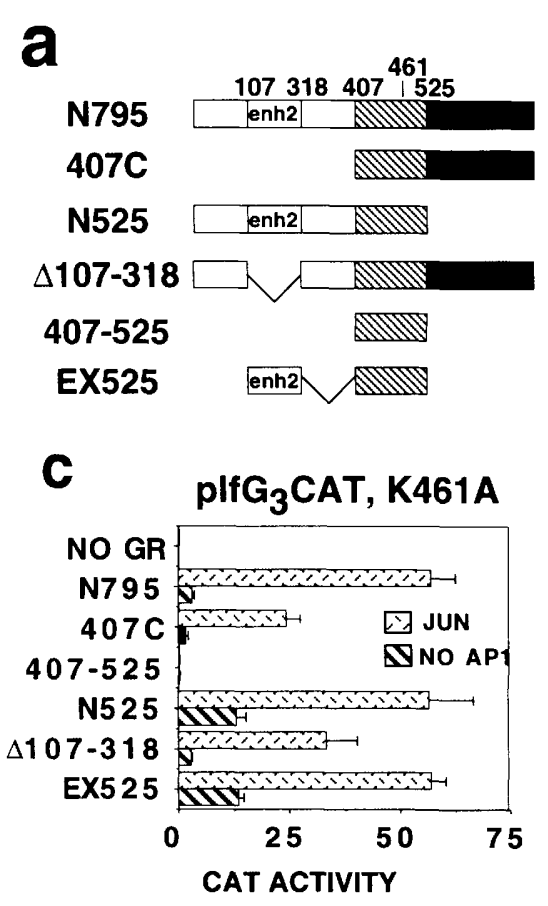
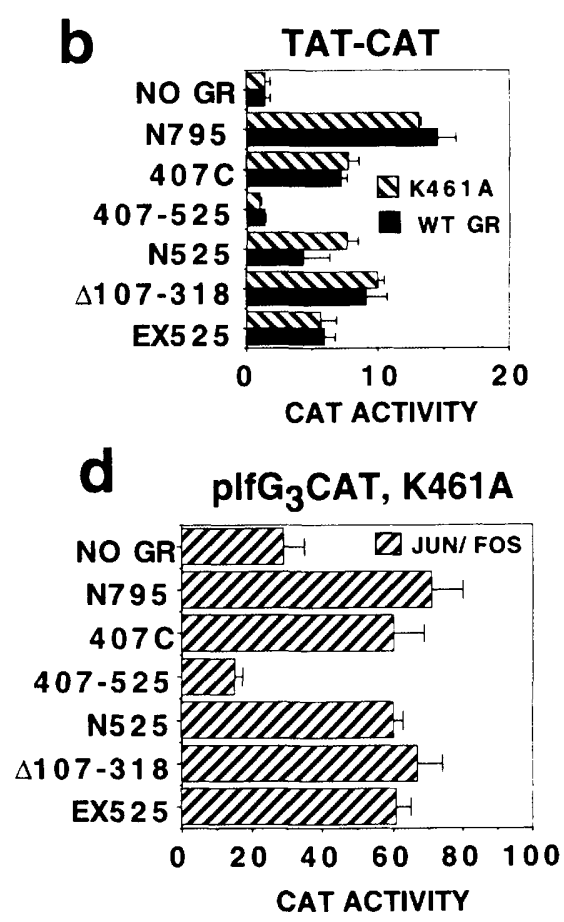

Figure 5. Activities of deletion derivatives of the K461A mutant from simple and composite GREs. (a) Schematic representation of rat GR and the various deletion constructs used in this experiment. $(b)$ Effect of deletions of wild-type GR and K461A on expression from the simple GRE reporter TAT-CAT. At $2 \mu \mathrm{g}$ of transfected GR expression plasmid used in these experiments, wild-type and K461A GR yielded equivalent levels of activation from the reporter TAT-CAT; at DNA levels below $0.2 \mu \mathrm{g}$, wild-type GR activated transcription more strongly than did GRK461A. (c) Effect of deletions on the activity of the K461A GR mutant from the composite GRE reporter, plfG $_{3}$ CAT in the absence or presence of cotransfected c-Jun. (d) Effect of deletions on the activity of the K461A GR mutant from plfG $_{3}$ CAT in the presence of cotransfected c-Jun and c-Fos. All assays were in transiently transfected mouse F9 cells in the presence of $0.1 \mu \mathrm{M}$ dexamethasone. Data are the average of two transfections carried out in triplicate; error bars represent standard error of the mean. 
derivatives from plfG ${ }_{3} \mathrm{CAT}$ in the presence of c-Jun (Fig. 5 c) or c-Jun and c-Fos (Fig. 5d) were similar to those from TAT-CAT (Fig. 5b). Thus, a single activation domain was sufficient for nearly full activation, whereas 407525 failed to activate. Note that repression by wild-type GR from plfG $_{3}$ CAT in the presence of c-Jun-c-Fos requires both amino- and carboxy-terminal sequences (Pearce and Yamamoto 1993; J.R. Thomas, J.N. Miner, W. Liu, M.d.M. Vivanco, and K.R. Yamamoto, in prep.; D.B. Starr, unpubl.).

Together, the deletion analyses yielded several conclusions. First, as with wild-type GR at a simple GRE, the ZBR and a functional activation domain are necessary and sufficient for transcription activation by K461 A from plfG $_{3}$ CAT. Second, either of the two activation domains of GR, or the heterologous VP16 activation domain (D.B. Starr, unpubl.) can provide a functional activation domain for K461A. Finally, the K461A mutation does not create an adventitious activation domain within the ZBR, as the 407-525 K461A derivative fails to activate transcription from either TAT-CAT (Fig. 5b) or plfG ${ }_{3}$ CAT in the presence or absence of AP1 (Fig. 5 c,d). We suggest that the K461A mutants employ the same activation domains that are used at simple and composite elements by the wild-type GR under normal activating conditions.

\section{GR dimerization is required for K461 A activation}

Interaction of the GR ZBR with a single simple GRE results in cooperative dimerization (Tsai et al. 1988; Luisi et al. 1991; J.H. Hill, J. Lefstin, J. Miner, K.R. Yamamoto, and C.A. Royer, in prep.). Mutation of residues whose side chains are thought to define the dimer interface (Luisi et al. 1991) confirmed that this interface is essential for transcription activation from the simple GRE (Yamamoto et al. 1993; Lefstin et al. 1994; Thomas et al., in prep.), but revealed that it is dispensable for repression from the colA tethering GRE (Heck et al. 1994) or the plfG composite element (Yamamoto et al. 1993; J.R. Thomas, J.N. Miner, W. Liu, M.d.M. Vivanco, and K.R. Yamamoto, in prep.).

To test whether K461A-mediated transcription activation from colA or plfG requires the defined dimer interface, we first mutated to alanine two amino-acid residues within the interface (J.R. Thomas, J.N. Miner, W. Liu, M.d.M. Vivanco, and K.R. Yamamoto, in prep.), R479 and N491, to produce the mutant RN. We then constructed a triple mutant, KRN, which bears those mutations together with the K461A mutation. We found that in the absence of AP1, K461A but not KRN, activated transcription from plfG $_{3} \mathrm{CAT}$ (Fig. 6a)-consistent with the idea that K461A at plfG and wild-type GR at a simple GRE are conformationally similar, and therefore require the same receptor surfaces for activation from the two elements. In the presence of c-Jun, activation by KRN was $\sim 10$-fold weaker than that conferred by K461A (Fig. 6a), suggesting that the structural requirements for activation in this context are again similar to those at the simple GRE.
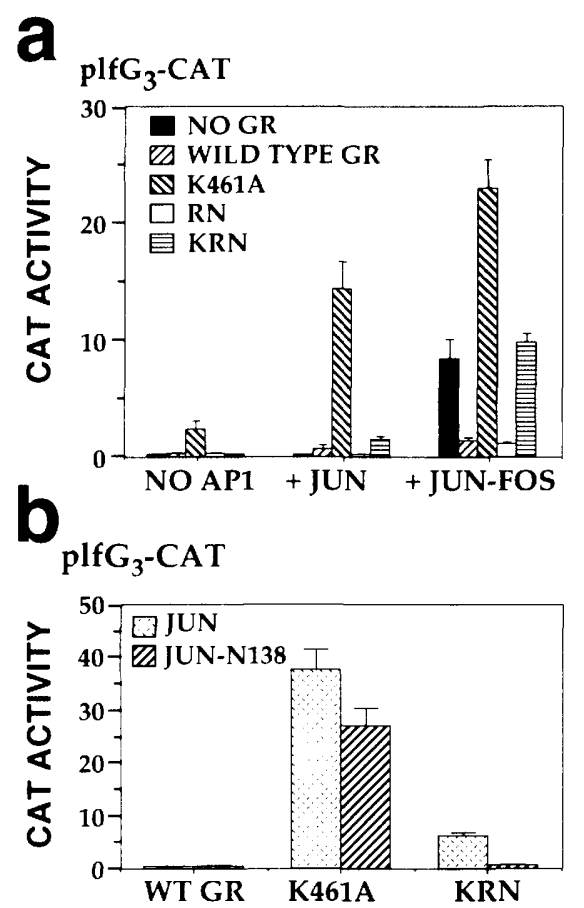

Figure 6. The effect of the dimer interface mutations R479A and N491A on the activity of K461A. (a) Activity of wild-type GR, K461A, R479A/N491A (RN), and K461A/R479A/N491A (KRN) from the composite GRE plfG, in the absence of APl, or in the presence of c-Jun, or c-Jun and c-Fos. Expression from reporter plf $\mathrm{G}_{3}$-CAT was assayed in the presence of $0.1 \mu \mathrm{M}$ dexamethasone in transiently transfected mouse F9 cells as described in Materials and methods. (b) Activity of wild-type GR, K461A, and $\mathrm{K} 461 \mathrm{~A} / \mathrm{R} 479 \mathrm{~A} / \mathrm{N} 491 \mathrm{~A}$ (KRN) from reporter $\mathrm{plfG}_{3}$-CAT was assayed as in $a$ but in the presence of cotransfected c-Jun or c-JunN138. Data are the average of two transfections carried out in triplicate; error bars represent standard error of the mean.

It seemed that the low level of residual activation conferred by KRN at plfG in the presence of c-Jun might reflect stimulation of the c-Jun activation domain, rather than use of a GR activation surface. To test this possibility, we used a deletion mutant of Jun, N138, which lacks the primary activation domain of Jun, but is competent to dimerize and bind DNA (Baichwal and Tjian 1990). With N138 as the sole source of AP1, K461A strongly activated expression from plfG $_{3} \mathrm{CAT}$, whereas KRN exhibited little or no activity (Fig. 6 b). We conclude that the strong synergy of $\mathrm{K} 461 \mathrm{~A}$ and c-Jun at plfG reflects a stimulation of the activation surfaces both of GR and of c-Jun. Weakening of the GR dimerization interface abrogates formation of the GR activation surfaces in this context, although K461A nevertheless interacts with and stimulates c-Jun.

Finally, in the presence of c-Jun and c-Fos at plfG (Fig. 6a) or colA (data not shown), the KRN triple mutant was virtually inactive; RN repressed as strongly as did wildtype GR, confirming previous findings (J.R. Thomas, J.N. Miner, M.d.M. Vicanco, and K.R. Yamamoto, in prep.), whereas K461A activated in this context. Consistent 
with our earlier findings (Figs. 2c,4,5d), we suggest from this result that the K461A causes misinterpretation of the repression context signaled by the plfG-c-Jun-c-Fos complex, but that the KRN receptor fails to activate because it lacks the dimer interface necessary to achieve the activating conformation.

\section{Genetic isolation of K461A-like mutations in GR}

As a step toward analyzing the role of $\mathrm{K} 461$ in signal interpretation and determination of transcriptional regulatory activity by GR, we sought to identify other GR amino-acid residues that might also be involved. Our approach was to screen in yeast for GR mutants with a K461 A-like phenotype. As in mammalian cells (see Fig. $2 \mathrm{~b}$ ), K461A in $S$. cerevisiae activates transcription strongly from plfG $_{3}-\beta$-gal, whereas wild-type GR does not (Fig. 7a). We randomly mutagenized the ZBR (amino acids $407-556$ ) or the transcription regulatory region enh2 (amino acids 107-318) within the GR derivative, N556, which lacks the carboxy-terminal signaling domain and is therefore hormone-independent, and

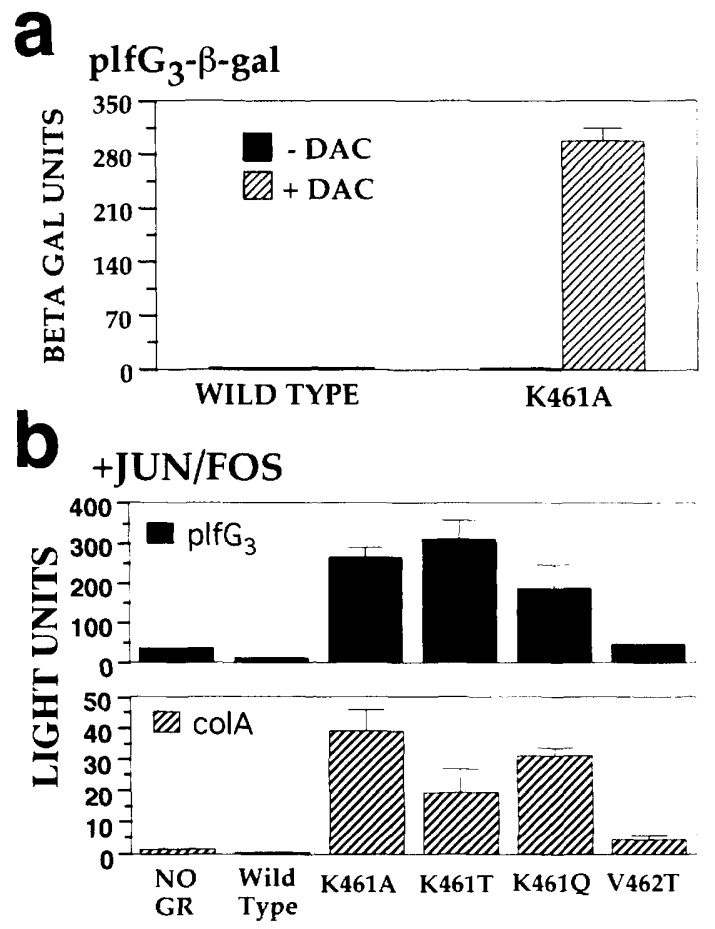

Figure 7. Activities of K461 A and K46l A-like mutants isolated in yeast. (a) Effect of the GR-K461A mutation on expression from reporter $\mathrm{plfG}_{3}-\beta$.gal in $S$. cerevisiae. Yeast cultures were propagated for $8 \mathrm{hr}$ in the absence or presence of $1 \mu \mathrm{M} \mathrm{DAC}$ as described in Materials and methods. (b) Activities of K461Alike mutants isolated in a yeast screen and tested in mammalian cells. Expression from the plfG $3-$ Luc and colA-Luc reporters was assayed in the presence of c-Jun and c-Fos in transiently transfected mouse F9 cells in the presence of $0.1 \mu \mathrm{M}$ dexamethasone as described in Materials and methods. Data are the average of two transfections done in duplicate; error bars represent standard error of the mean. screened in yeast for mutants that activated transcription from plfG.

Among 30,000 yeast colonies carrying the mutagenized enh2 region, we failed to recover any mutants with elevated reporter activity. However, we isolated 14 such mutants from 30,000 colonies bearing the mutagenized ZBR. Sequencing revealed that 13 of the mutants contained single-amino-acid substitutions: 12 of these were identical, K461Q, and the other was V462T. The last mutant contained two amino-acid substitutions, K461T and K465I, but further analysis demonstrated that the K461T lesion was responsible for the phenotype. The mutants were then assayed in transiently transfected murine F9 cells with plfG ${ }_{3}$ Luc and colA-Luc reporters. In both cases, the mutants with K461 alterations activated strongly, and the V462T was weak, displaying about $10 \%$ of the activity of K461 A (Fig. $7 \mathrm{~b}$ ). We conclude that $\mathrm{K} 461$ is a key determinant of GR transcriptional regulatory activity in GRE contexts at which GR normally represses or is inactive, and that V462 may have a minor role.

The K461-equivalent residue has a similar role in $M R$ and $R A R \beta$

Of the over 80 intracellular receptors cloned to date, the $\mathrm{K} 461$-equivalent position is occupied by lysine in all except Drosophila tailless, where it is alanine (Pignoni et al. 1990), and its avian homolog Tlx, where it is serine (Yu et al. 1994). To test whether the novel role of K461 detected in GR is conserved among other IRs, we made the equivalent $\mathrm{K} 461 \mathrm{~A}$ mutation in the mineralocorticoid receptor (MR) and the retinoic acid receptor $\beta$ (RAR $\beta)$.

RAR $\beta$ represses transcription from the colA-c-Junc-Fos tethering element (Schule et al. 1991; Yang-Yen et al. 1991) but not from the plfG-c-Jun-c-Fos composite element (J.R. Thomas, J.N. Miner, W. Liu, M.d.M. Vivanco, and K.R. Yamamoto, in prep.). We analyzed the K461A-equivalent mutation of hRAR $\beta, \mathrm{K} 102 \mathrm{~A}$, in CV1 cells, which lack endogenous RAR and contain endogenous $\mathrm{c}$-Jun and c-Fos. In contrast to the fivefold repression by transfected wild-type RAR $\beta$ from colA-Luc, RAR $\beta-K 102 A$ activated transcription 25- to 40-fold (Fig. 8a). The mutant also activated transcription sevenfold from plfG ${ }_{3}$ Luc (Fig. 8 b), presumably indicating that the K102A mutant had gained the capacity to tether to APl bound at plfG. Therefore, as with K461 in GR, K102 in RAR $\beta$ is important for signal interpretation. Our results also reveal that RAR $\beta-K 102 \mathrm{~A}$ has lost the ability of wild-type RAR $\beta$ to distinguish between APl bound to colA and to plfG.

MR activates transcription from simple GREs but is inactive at plfG (Pearce and Yamamoto 1993) or colA (Heck et al. 1994) either in the presence or absence of APl. We found that the K461A-equivalent mutation of rat MR, K625A, activated transcription $\sim 20$-fold from plfG $_{3}$ Luc (Fig. 8b) and three- to fivefold from colA-Luc (Fig. 8a). Therefore, the K461A-equivalent is a critical determinant of transcriptional regulatory activity in at least three different IRs, implying that signaling infor- 

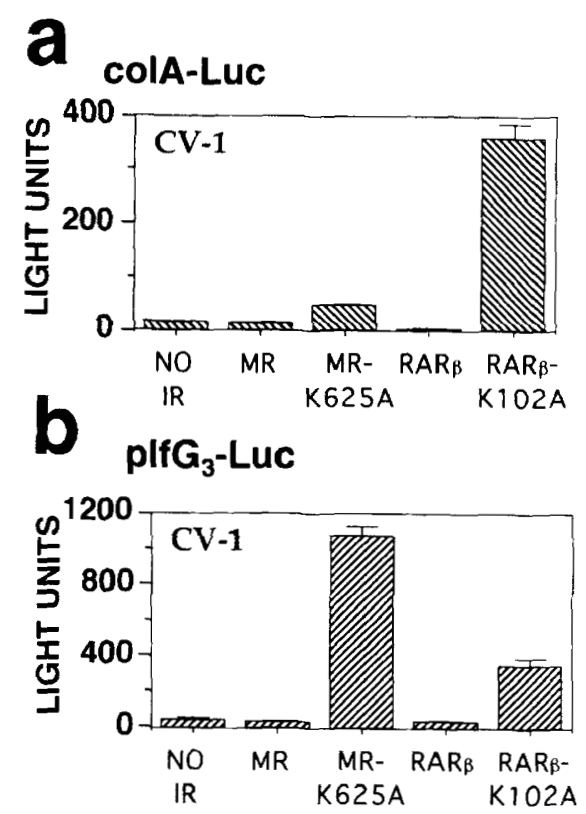

Figure 8. Effects of K461A-equivalent mutations of $M R$ (K625) and $\operatorname{RAR} \beta(\mathrm{K} 102)$ on their activities from tethering and composite GREs. Expression from the reporter colA-Luc $(a)$ or plfG $\mathrm{G}_{3}$-Luc $\langle b|$ was assayed in the presence of either $1 \mu \mathrm{M}$ corticosterone (MR, MR-K625A) or $0.1 \mu \mathrm{M}$ all trans-retinoic acid (RARß, RARß-K102A) in transiently transfected CV-1 cells as described in Materials and methods. Data are the average of two transfections carried out in triplicate; error bars represent standard error of the mean.

mation encoded in response elements may be interpreted through a common mechanism by this family of factors.

\section{Discussion}

Previous studies demonstrated that the transcription activation functions of hormone-bound GR are blocked before receptor association with a functional GRE, and that it is the ZBR that confers this inhibition (Lefstin et al. 1994). This led to speculation that GR might obtain signaling information from the particular GREs to which it binds, and that response elements may thereby serve as allosteric effectors that participate in specifying the functional state of the regulatory regions.

These findings were surprising because the DNA-binding domains from transcription regulators such as Gal4p and $\lambda c I$ fail to inhibit activation domains in the absence of response element binding, and therefore squelch transcription and inhibit cell growth when overexpressed in yeast. We speculate that certain factors such as GR, which activate or repress different genes in different cell and physiologic settings, must have acquired multiple ways to sense and distinguish distinct contexts, including response elements. In contrast, Gal4p may not require this extra layer of regulatory complexity, as it activates only a few genes in a simple and essentially constant cell context.

In any case, GR and many other regulators display dif- ferent regulatory activities in different contexts. In particular, in three classes of GREs distinguished by distinct DNA sequences, cofactor, and DNA-binding requirements, GR may activate or repress transcription or may bind and fail to influence transcription (Diamond et al. 1990; Jonat et al. 1990; Schule et al. 1990; Yang-Yen et al. 1990; Tsai and O'Malley 1994). In this study we show that single base-pair mutations in one class of GRE could switch GR behavior to that normally observed in a different class of GRE, and that a conserved residue in the intracellular receptor superfamily, K461 in the rat GR, has a critical role in interpreting the signaling information provided by the response elements at which they bind. Therefore, receptors with various mutations at the K461-equivalent position activated transcription in contexts at which their wild-type counterparts repressed or were inactive. Further genetic studies suggested that $\mathrm{K} 461$ is a critical residue in defining this novel function.

Although an alternative interpretation is that $\mathrm{K} 461 \mathrm{~A}$ is locked into an active conformation independent altogether of a GRE, indirect evidence appears to contradict this notion. In this scenario, for example, overexpressed $\mathrm{K} 461 \mathrm{~A}$ would strongly squelch transcription in yeast and mammalian cells, and inhibit yeast growth, as seen with VP16 fusions to Gal4p or $\lambda \mathrm{cI}$, and with GR mutants that are locked in the activation mode (Lefstin et al. 1994). However, K461A neither squelches transcription more strongly than does wild-type GR (data not shown), nor does it produce a growth defect in yeast (J.A. Lefstin and K.R. Yamamoto, unpubl.). In addition, were K461A locked in an active conformation, it might stably dimerize when not associated with a GRE, or activate even in the absence of dimerization. On the contrary, mutations that disrupt the dimer interface compromise K461 A-mediated transcription activation (Fig. 6), and neither hydrodynamic studies nor glutaraldehyde crosslinking suggest that K461A dimerizes more readily than does wildtype GR (data not shown).

In principle, a portion of the behavior of the K461 A mutant might be accounted for if it were to display elevated affinities for its GRE targets. However, K461A and wild-type GR differ little in their affinities either for plfG (Fig. 3b) or GST-Iun (D.B. Starr, unpubl.). Moreover, increased affinity alone could not account for the reversal of GR regulation from repression to activation at $\mathrm{plfG}$ in the presence of $c$-Jun-c-Fos.

Based on these findings, we propose as a working model (Fig. 9) that K461 might comprise part of a "reversible lock", constraining the regulatory surface of GR in a repressing conformation in response to GRE signals at which the receptor acts negatively, but permitting it to adopt an activating conformation in GRE contexts in which GR activates. The K461A mutation, then, would permit the shift to the activating conformation in response to many or all GRE signals. According to this view, K461 interprets GRE signals by serving as a determinant of GR conformation and hence, function (Fig. 9). To our knowledge, similar studies have not been carried out with other regulators, including MCMl and NFkB, both of which have been reported to undergo response 


\section{WILD TYPE GR GR-K461A}

SIMPLE
GRE
TETHERING
GRE
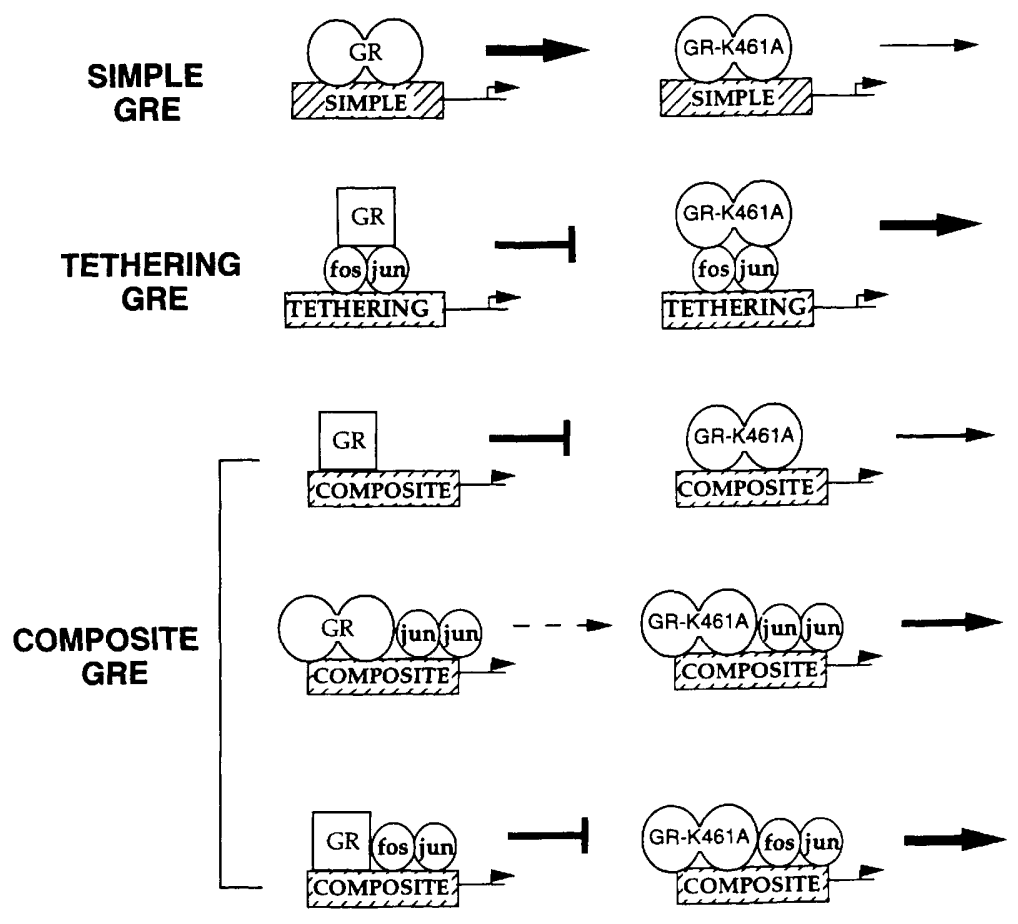

Figure 9. Model of GR and GR-K461A function at simple, tethering, and composite GREs. Circled form of GR indicates activating conformation; square GR denotes repressing conformation. Thickness of arrows over gene reflects relative activation; T-bar over gene denotes repression. element-specific conformational changes on DNA binding (Tan and Richmond 1990: Fujita et. al. 1992); it would be intriguing to determine whether such simple molecular switches, such as that evidenced by K461 in $\mathrm{GR}$, are commonly employed.

For simplicity, we have considered the GR transcriptional regulatory domain in terms of two alternative functional surfaces, conferring either activation or repression. Notably, however, multiple distinct conformations might exist, specifying interaction surfaces for multiple targets, some that act positively, others negatively. By this view, GR could interact with different target factors in different GRE contexts. As allosteric effectors, the various GRE contexts would modulate complex equilibria between different functional conformations, some resulting in net activation, others in net repression. According to this scheme, $\mathrm{K} 461$ would be a crucial determinant of the equilibria between the various conformations, and the K461A mutation would drive them strongly in the direction of activating conformations.

Clearly, the mechanisms by which K461 might exert its effects are not known. At simple GREs, the K461 side chain has a direct role in DNA sequence recognition by being involved in direct and water-mediated hydrogen bonds to nucleotide bases. Although the positions of K461 in the GR-plfG complex have not been determined, the modest effect of the K461A mutation on that interaction suggest that $\mathrm{K} 461$ does not have a similar direct role.

Conceivably, K461 might itself comprise part of a repression surface in the context of plfG-c-Jun-c-Fos or colA that is disabled when this residue is mutated to alanine. However, we do not favor this model and sug- gest instead that K461 may allosterically control the activities (and presumably, the conformations) of the transcriptional regulatory region. First, the overall fold of the mutant ZBR is probably generally similar to that of the wild type, and the ZBR likely approaches plfG in an approximately similar manner as it does a simple element. In addition, it has been reported that the GR ZBR interaction with c-Jun (for review, see Yamamoto et al. 1993; Herrlich and Ponta 1994; Saatcioglu et al. 1994) compromises GR-GRE binding (Yang-Yen et al. 1990), perhaps implicating the DNA-binding surface of the ZBR in its tethering interaction with AP1. These results imply that K461 may be close to the GRE in all three contexts, consistent with the view that K461 interprets and transduces context information from the GRE to the transcription regulatory domain.

To assess these notions in detail, it will be essential to obtain molecular structure information about GR complexes with plfG and colA. Unfortunately, attempts to infer structural differences by measuring differential sensitivities to limited proteolysis have yielded negative results in our hands; experiments with seven different proteases have not revealed altered cleavage sensitivities (D.B. Starr, unpubl.). Efforts are currently underway to obtain detailed structural information using NMR and $x$-ray diffraction. Without some assessment of molecular structure, it remains a matter of speculation that the response element interaction provokes its effects on receptor activities through conformational effects on receptor structure. However, this notion serves well to organize the current information in a consistent way, and to illuminate clear predictions and foci for future studies. 
Our demonstration that K461A-equivalent mutations in other intracellular receptors produce phenotypes at plfG and colA that are similar to those seen with the GR mutant suggests that this conserved lysine residue may have a common role in signal transduction from hormone response elements throughout the superfamily. It will be interesting to examine other repression contexts, and these studies in turn may advance our understanding of the mechanisms of repression per se. For example, the thyroid hormone receptor (TR) represses transcription in the absence of hormone when bound to certain response elements, such as DR4, apparently by associating with a corepressor, TRAC (Chen and Evans 1995; Horlein et al. 1995; Kurokawa et al. 1995). In preliminary experiments, we found normal repression at DR4 by the unliganded K461A equivalent mutant of TR, whereas the mutant protein in the presence of thyroid hormone produced aberrant activation in the colA-APl context (D.B. Starr, unpubl.).

We suggest that many regulatory factors that govern global physiologic circuits in complex metazoans may be "molecular mosaics" comprised of many potential functional surfaces. The precise structures and roles of such surfaces remain to be described, but genetic studies in simpler systems have begun to define molecular "patches" at the sites of positive and negative control mutations, which appear to effect interactions between the regulator and the transcription machinery (Guarente et al. 1982; Komachi et al. 1994; Niu et al. 1994). The implication for factors such as GR is that they must extract context information from their surroundings that specify which facets of the mosaic will form, and thereby whether activating or repressing surfaces will be presented to the transcription machinery. By this view, the present study defines a new class of mutations that appears to cause inappropriate presentation of activation surfaces in repressing contexts. Our findings show that response elements, in addition to their obvious function of recruiting factors into the proximity of promoters to be regulated, provide context information that contributes to the ability of a single factor to confer many distinct regulatory patterns.

\section{Materials and methods}

\section{Plasmids}

The reporter plasmid plfG $_{3}$ Luc contains three tandem copies of the proliferin GRE (Diamond et al. 1990) upstream of the Drosophila alcohol dehydrogenase (Adh) minimal promoter ( -33 to +53 ) and the luciferase gene (luc) (de Wet et al. 1987). The reporter colA-Luc (W. Matsui and K.R. Yamamoto, unpubl.) is similar to $\mathrm{plfG}_{3}$ Luc except that the three copies of plfG have been replaced with a single consensus AP1 site (TGAGTCA) from the collagenase gene. The construct $\mathrm{plf}_{3} \mathrm{CAT}$ (Diamond et al. 1990) is similar to $\mathrm{plfG}_{3}$ Luc except that the luciferase gene has been replaced by the chloramphenicol acetyltransferase (CAT) gene. TAT-CAT contains a single copy of the simple GRE component of the rat tyrosine aminotransferase gene (Jantzen et al. 1987) upstream of the Herpes simplex virus thymidine kinase promoter $(-148$ to +1 ; McKnight and Kingsbury 1982) driving the CAT gene. GTCO (Pearce and Yamamoto
1993) contains a simple GRE derived from the mouse mammary tumor virus long terminal repeat (MMTV LTR) upstream of the thymidine kinase promoter $(-109$ to +1$)$ driving the CAT gene.

The mutant $\mathrm{plfG}_{3}$ Luc reporter constructs used in Figure 1 were made by synthesizing plfG oligonucleotides containing single transversion mutations, cloning them into p $\triangle O D L O / V i$ vanco et al. 1995), selecting by diagnostic endonuclease digestion those bearing three tandem inserts of the element, and sequencing the resultant constructs. Of 12 such transversion mutants tested, TG7 and AC17 displayed simple GRE activity, activating transcription in the absence of APl.

The GR expression vector 6RGR (Godowski et al. 1988), the MR expression vector 6RMR (Pearce and Yamamoto 1993), the $\beta$-galactosidase control, 6R $\beta$-gal (Pearce and Yamamoto 1993), the c-Jun expression plasmid, RSV-Jun (Baichwal and Tjian 1990), and the c-Fos expression plasmid, RSV-Fos (Baichwal and Tiian 1990) are SP65-based vectors in which the Rous sarcoma virus (RSV) promoter is used to drive expression of the respective genes. The RAR $\beta$ expression plasmid (Vivanco-Ruiz et al. 1991 ) is based on the SG5 vector (Promega). For the K461A, V462A, and R466A mutations in rat GR, a KpnI-PstI fragment from the plasmid 6RGR was cloned into Bluescript KS+ $[\mathrm{KS}+\mathrm{GR}(1-523)]$ and the mutations were introduced by standard protocols (Kunkel 1985). After dideoxy sequencing to confirm the presence of only the desired mutations, BstBI-PstI fragments from the mutagenized plasmids were cloned back into 6RGR. Mutations in MR and RAR $\beta$ were constructed in a similar fashion. The N525, 407C, and EX525 deletions of 6RGR are described in Godowski et al. (1987) and the K461A mutation was incorporated into them by substitution of appropriate fragments from 6RGR-K461A into these deletion constructs. 6RGR $(\Delta 107-318)$ and 6RGR-K461A $(\Delta 107-318)$ were made by cutting the full-length versions with $N c O$ I and Bsp $120 \mathrm{I}$, filling in with Klenow, and religating. The 407-525 constructs were made by deleting coding sequence for residues $1-407$ from KS + GR[1-523] using site-directed mutagenesis (Kunkel 1985). The KpnI-PstI fragments of the resulting plasmids were then subcloned into 6RGR-N525.

The bacterial expression plasmids for EX525-HMK and EX525(K461 A)-HMK were made as follows. BamHI fragments containing wild-type and $\mathrm{K} 461 \mathrm{~A}$ versions of GR[407-523] were cloned into the BamHI site of pETIld-HMK (kindly provided by M. Carey, University of California, Los Angeles). To create an in-frame fusion, these intermediate plasmids were restricted with $X \mathrm{maI}$ and $X$ hol, filled in with Klenow, and religated to yield pET[407-525]-HMK and pET[407-525-K461 A-HMK. Finally, a BstBI-XbaI fragment from T7-EX556 (Freedman et al. 1989) was cloned into the BstBI and XbaI sites of pET(407-525) HMK and pET[407-525-K461A]-HMK to create pET-EX525HMK and pET-EX525(K461A)-HMK. The resulting derivatives have a 5 amino-acid heart muscle kinase site (Arg-Arg-AlaSer-Vall fused at their carboxyl termini.

The yeast reporter plasmid plfG ${ }_{3}-\beta$-gal, was constructed by J. Lefstin (University of California at San Francisco) and consists of three plfG-containing oligonucleotides (TCGACGGCTACTCACAGTATGATTTGTTTTC) cloned into the Xhol site of pUCASS, a Ura-marked, $2 \mu$ plasmid (Guarente and Ptashne 1981).

\section{Transient transfection}

F9 mouse embryonic carcinoma and CV-1 cells were transiently transfected as described (Pearce and Yamamoto 1993). Briefly, cells from two partially confluent $(50 \%) 10-\mathrm{cm}$ plates grown in Dulbecco's modified Eagle's medium (DME-H16) supplemented with $10 \%$ fetal calf serum were suspended in $96 \mathrm{ml}$ of the same medium and aliquoted into $246-\mathrm{cm}$ plates either $24 \mathrm{hr}$ 
(CV-1) or $7 \mathrm{hr}$ (F9) before transfection by the calcium phosphate precipitation method (Diamond et al. 1990). After exposure to the DNA-calcium phosphate mixture overnight (14 hr), the F9 cells were glycerol shocked ( $15 \%$ glycerol in DME-H16 lacking serum) for $1 \mathrm{~min}$, washed twice with PBS lacking calcium and magnesium, and then incubated for $24 \mathrm{hr}$ in fresh medium containing $10 \%$ charcoal-stripped fetal calf serum with or without hormone. CV-1 cells were treated similarly except that the glycerol shock was omitted. Hormone concentrations used were $0.1 \mu \mathrm{M}$ dexamethasone, $1 \mu \mathrm{M}$ corticosterone, and $0.1 \mu \mathrm{M}$ all transretinoic acid. Each transient transfection included $2 \mu \mathrm{g}$ of reporter plasmid, $2 \mu \mathrm{g}$ of intracellular receptor expression plasmid (or the empty vector when no intracellular receptor construct was transfected), and $0.25 \mu \mathrm{g}$ of $\beta$-galactosidase control plasmid. Where noted, either $0.5 \mu \mathrm{g}$ of RSV-Jun or $0.25 \mu \mathrm{g}$ each of RSVJun and RSV-Fos was included in the transient transfections.

Luciferase activity was determined by resuspending PBSwashed cells in $100 \mu \mathrm{l}$ of Reporter Lysis buffer (Promega) and incubating at room temperature for $15 \mathrm{~min}$. Cellular debris was removed by centrifuging for $5 \mathrm{~min}$ at $15,000 \mathrm{~g}$ at $4^{\circ} \mathrm{C}$. Ten microliters of supernatant was assayed for luciferase activity using $100 \mu \mathrm{l}$ of Luciferase Assay reagent (Promega) in a Monolight 2001 luminometer. Light emission was integrated for $30 \mathrm{sec}$ at room temperature. CAT activity was determined by resuspend-

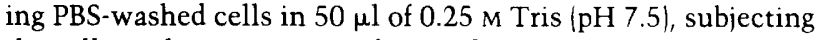
the cells to three successive freeze-thaw cycles /with a dry ice/ ethanol bath) and removing cell debris by centrifuging for $5 \mathrm{~min}$ at $15,000 \mathrm{~g}$ at $4^{\circ} \mathrm{C}$. Samples were then heat treated $15 \mathrm{~min}$ at $65^{\circ} \mathrm{C}$ ) and recentrifuged (5 min, $15,000 \mathrm{~g}$ at $4^{\circ} \mathrm{C}$ ). Using a nonchromatographic procedure described previously (Sleigh 1986), $25 \mu \mathrm{l}$ of supernatant was assayed for CAT activity. After background subtraction, luciferase or CAT activity was normalized to the activity of the $\beta$-galactosidase internal transfection control which was analyzed as described (Vivanco et al. 1995). Activity of the RSV LTR used to express the GR and $\beta$-galactosidase was not affected by experimental conditions.

Protein purification

EX525-HMK and EX525(K461A)-HMK were overexpressed in, and purified from, the BL21/DE3 strain of Escherichia coli as described previously (Freedman et al. 1989) except that only one column, CM-Sepharose, was used. Briefly, the cell pellets were processed as described and dialyzed in $\mathrm{HZ}$ buffer $\mid 10 \%$ glycerol, $50 \mathrm{~mm}$ HEPES (pH 8.0), $0.5 \mathrm{~mm}$ EDTA] to $50 \mathrm{~mm} \mathrm{NaCl}$. The extract was then loaded onto a CM-Sepharose column at $50 \mathrm{~mm}$ $\mathrm{NaCl}$ in $\mathrm{HZ}$ buffer and eluted with a $50-300 \mathrm{~mm} \mathrm{NaCl}$ gradient in $\mathrm{HZ}$ buffer. The peak of protein elution was at $\sim 190 \mathrm{~mm}$ $\mathrm{NaCl}$. The proteins were $\sim 90 \%$ pure by Coomassie staining.

\section{Gel mobility shift assay}

The concentrations of CM-Sepharose purified EX525-HMK and EX525(K461 A)-HMK indicated in Figure 2 were incubated with either $\mathrm{s} 3$ - or plfG-containing ${ }^{32} \mathrm{P}$ end-labeled oligonucleotides in a total reaction volume of $9 \mu \mathrm{l}$. Reaction conditions were as follows: $20 \mathrm{mM}$ HEPES (pH 7.5), $100 \mathrm{~mm} \mathrm{NaCl}, 10 \%$ glycerol, $1 \mathrm{~mm}$ EDTA, $0.05 \% \mathrm{NP}-40,0.1 \mathrm{mg} / \mathrm{ml}$ of BSA, and 1 mM DTT. After $30 \mathrm{~min}$ at room temperature, the entire reaction was loaded onto a $0.8-\mathrm{mm}$ thick, $4 \%$ polyacrylamide gel and electrophoresed in $1 \times$ TGE (25 mM Tris base, $190 \mathrm{~mm}$ glycine, $1 \mathrm{~mm}$ EDTA) until the bromphenol blue had traversed $10 \mathrm{~cm}$ from the bottom of the well. The gel was then transferred to Whatman 3MM paper, dried under heat and vacuum, and exposed to Hyperfilm overnight. The gel was processed to determine the fraction of DNA bound at each concentration (Hoopes et al. 1992). Briefly, complex formation was quantitated by excising the regions corresponding to complexed and free DNA and measuring the radioactivity in a liquid scintilla- tion counter. The fraction bound was then calculated as the radioactivity in the complex divided by the radioactivity of both free and complexed DNA.

\section{Yeast screens}

The yeast strain used was $S M 10$ (Wu et al. 1993), in which yeast $\mathrm{APl}$ is disrupted by the His 3 gene. Other relevant genotypic markers of SM10 include leu2-3, 112, ura3-52, his3-4200, trp1$\Delta 901$, lys2-801, suc2- $\Delta 9$, and $\mathrm{MeI}^{-}$

The library of $\mathrm{Zn}$-binding regions of GR mutants was created as follows. An EcoRI-Xhol fragment from the plasmid pG-D (Schena and Yamamoto 1988) was cloned into KS + and singlestranded DNA isolated as described (Kunkel 1985). The singlestranded DNA was then treated with either $18 \mathrm{M}$ formic acid for $50 \mathrm{sec}$ at $20^{\circ} \mathrm{C}, 18 \mathrm{M}$ hydrazine for $4.5 \mathrm{~min}$ at $20^{\circ} \mathrm{C}$, or $1 \mathrm{M}$ sodium nitrite for $2.5 \mathrm{~min}$ at $20^{\circ} \mathrm{C}$. These conditions yielded a mutation frequency of approximately one hit per molecule. The opposite strand of the mutagenized single-stranded DNA was then transcribed with reverse transcriptase and the EcoRI-XhoI fragment cloned back into pG-D. The pool of enh2 mutants was kindly provided by J.A. Iniguez-Lluhi and was created by a PCR strategy (Leung et al. 1989) that yielded a mutation rate of $\sim 10$ hits over the 600-bp enh 2 region /corresponding to amino acids $106-318$ ).

The mutant GR libraries were then transformed into SM10 containing the $\mathrm{plfG}_{3}-\beta$-gal reporter and plated onto selective media (SD - ura, - trp) at a density of $\sim 10^{3}$ colonies per plate. The colonies were then replica-plated and surveyed for $\beta$-gal activity as described (Bohen and Yamamoto 1993). GR expression plasmids were isolated from the colonies displaying the highest $\beta$-gal activity, and were retransformed into SM10 strains carrying the $\mathrm{plfG}_{3}-\beta$-gal reporter to confirm their phenotypes. The mutated region was sequenced by conventional methods. For quantitation of $\beta$-gal activities, saturated yeast cultures were diluted 1:6 into fresh medium lacking or containing $1 \mu \mathrm{M}$ deacylcortivazol (DAC), a synthetic glucocorticoid (Garabedian and Yamamoto 1992) and grown for an additional 8 $\mathrm{hr}$ at $30^{\circ} \mathrm{C}$; enzyme activities were assayed as described (Schena and Yamamoto 1988; Garabedian and Yamamoto 1992).

\section{Acknowledgments}

We thank M. Carey for the plasmid pETlld-HMK, J. Lefstin for the plasmid plfG $3-\beta$-gal, J.A. Iniguez-Lluhi for the mutant enh2 library, B. Maler for cheerfully providing purified GR derivatives, and L.K. Bruhn, R. Grosschedl, J.A. Iniguez-Lluhi, A. Kralli, J. Lefstin, and M. Privalsky for helpful comments on the manuscript. This work was supported by grants from the $\mathrm{Na}$ tional Science Foundation and the National Institutes of Health. D.B.S. is a Sterling Winthrop Fellow of the Life Sciences Research Foundation.

The publication costs of this article were defrayed in part by payment of page charges. This article must therefore be hereby marked "advertisement" in accordance with 18 USC section 1734 solely to indicate this fact.

\section{References}

Baichwal, V.R. and R. Tijan. 1990. Control of c-Jun by interaction of a cell-specific inhibitor with regulatory domain $\delta$ : Differences between v- and c-Jun. Cell 63: 815-825.

Ballard, P.L. 1989. Hormonal regulation of pulmonary surfactant. Endocrinol. Rev. 10: 165-181.

Bohen, S.P. and K.R. Yamamoto. 1993. Isolation of Hsp90 mutants by screening for decreased steroid receptor function. Proc. Natl. Acad. Sci. 90: 11424-11428. 
Chen, J.D. and R.M. Evans. 1995. A transcriptional co-repressor that interacts with nuclear hormone receptors. Nature 377: 454-457.

Dalman, F.C., L.C. Scherrer, L.P. Taylor, H. Akil, and W.B. Pratt. 1991. Localization of the $90-\mathrm{kDa}$ heat shock proteinbinding site within the hormone-binding domain of the glucocorticoid receptor by peptide competition. J. Biol. Chem. 266: 3482-3490.

de Wet, J.R., K.V. Wood, M. DeLuca, D.R. Helinsk, and S. Subramani. 1987. Firefly luciferase gene: Structure and expression in mammalian cells. Mol. Cell. Biol. 7: 725-737.

Diamond, M., J.N. Miner, S.K. Yoshinaga, and K.R. Yamamoto. 1990. Transcription factor interactions: Selectors of positive or negative regulation from a single DNA element. Science 249: 1266-1272.

Freedman, L.P., B.F. Luisi, Z.R. Korszun, R. Basavappa, P.B. Sigler, and K.R. Yamamoto. 1988. The function and structure of the metal coordination sites within the glucocorticoid receptor DNA binding domain. Nature 334: 543-546.

Freedman, L.P., S.K. Yoshinaga, J.N. Vanderbilt, and K.R. Yamamoto. 1989. In vitro transcriptional enhancement by purified derivatives of the glucocorticoid receptor. Science 245: 298-301.

Frenkel, B., M. Montecino, J.L. Stein, J.B. Lian, and G.S. Stein. 1994. A composite intragenic silencer domain exhibits negative and positive transcriptional control of the bone-specific osteocalcin gene: Promoter and cell type requirements. Proc. Natl. Acad. Sci. 91: 10923-10927.

Fujita, T., G.P. Nolan, S. Ghosh, and D. Baltimore. 1992. Independent modes of transcriptional activation by the p50 and p65 subunits of NF-k B. Genes \& Dev. 6: 775-787.

Garabedian, M.J. and K.R. Yamamoto. 1992. Genetic dissection of the signaling domain of a mammalian steroid receptor in yeast. Mol. Biol. Cell 3: 1245-1257.

Giguere, V., S.M. Hollenberg, M.G. Rosenfeld, and R.M. Evans. 1986. Functional domains of the human glucocorticoid receptor. Cell 46: 645-652.

Godowski, P.J., S. Rusconi, R. Miesfeld, and K.R. Yamamoto. 1987. Glucocorticoid receptor mutants that are constitutive activators of transcriptional enhancement. Nature 325: 365368.

Godowski, P.J., D. Picard, and K.R. Yamamoto. 1988. Signal transduction and transcriptional regulation by glucocorticoid receptor-LexA fusion proteins. Science 241: 812-816.

Green, S. and P. Chambon. 1987. Oestradiol induction of a glucocorticoid response gene by a chimeraic receptor. Nature 325: 75-78.

Guarente, L. and M. Ptashne. 1981. Fusion of Escherichia coli Lac $\mathrm{Z}$ to the cytochrome $\mathrm{c}$ gene of Saccharomyces cerevisiae. Proc. Natl. Acad. Sci. 78: 2199-2203.

Guarente, L., J.S. Nye, A. Hochschild, and M. Ptashne. 1982. A mutant lambda repressor with a specific defect in its positive control function. Proc. Natl. Acad. Sci. 79: 2236-2239.

Hard, T., E. Kellenbach, R. Boelens, B.A. Maler, K. Dahlman, L.P. Freedman, J. Carlstedt-Duke, K.R. Yamamoto, J.-A. Gustafsson, and R. Kaptein. 1990. Solution structure of the glucocorticoid receptor DNA-binding domain. Science 249: $157-160$.

Heck, S., M. Kullman, A. Gast, H. Ponta, H.J. Rahmsdorf, P. Herrlich, and A.C.B. Cato. 1994. A distinct modulating domain in glucocorticoid receptor monomers in the repression of activity of the transcription factor AP-1. EMBO $/$. 13: 4087-4095.

Herrlich, P. and H. Ponta. 1994. Mutual cross-modulation of steroid-retinoic acid receptor and AP-1 transcription factors:
A novel property with practical implications. Trends Endocrinol. Metab. 5: 341-346.

Hollenberg, S.M. and R.M. Evans. 1988. Multiple and cooperative trans-activation domains of the human glucocorticoid receptor. Cell 55: 899-906.

Hoopes, B.C., J.F. LeBlanc, and D.K. Hawley. 1992. Kinetic analysis of yeast TFIID-TATA box complex formation suggests a multi-step pathway. J. Biol. Chem. 267: 1539-1547.

Hori, R. and M. Carey. 1994. The role of activators in assembly of RNA polymerase II transcription. Curr. Opin. Genet. Dev. 4: 236-244.

Horlein, A.J., A.M. Naar, T. Heinzel, J. Torchia, B. Gloss, R. Kurokawa, A. Ryan, Y. Kamei, M. Soderstrom, C.K. Glass, and M.G. Rosenfeld. 1995. Ligand-independent repression by the thyroid hormone receptor mediated by a nuclear receptor co-repressor. Nature 377: 397-404.

Howard, K.J. and C.W. Distelhorst. 1988. Evidence for intracellular association of the glucocorticoid receptor with the 90kDa heat shock protein. I. Biol. Chem. 263: 3474-3481.

Howard, K.J., S.J. Holley, K.R. Yamamoto, and C.W. Distelhorst. 1990. Mapping the Hsp90 binding region of the glucocorticoid receptor. I. Biol. Chem. 265: 11928-11935.

Imai, E., J.N. Miner, J.A. Mitchell, K.R. Yamamoto, and D.K. Granner. 1993. Glucocorticoid receptor-cAMP response element-binding protein interaction and the response of the phosphoenolpyruvate carboxykinase gene to glucocorticoids. I. Biol. Chem. 268: 5353-5356.

Jantzen, H.M., U. Strahle, B. Gloss, F. Stewart, W. Schmid, M. Boshart, R. Miksicek, and G. Schutz. 1987. Cooperativity of glucocorticoid response elements located far upstream of the tyrosine aminotransferase gene. Cell 49: 29-38.

Jonat, C., H.J. Rahmsdorf, K.-K. Park, A.C.B. Cato, S. Gebel, H. Ponta, and P. Herrlich. 1990. Antitumor promotion and antiinflammation: Down-modulation of AP-1 (Fos/Jun) activity by glucocorticoid hormone. Cell 62: 1189-1204.

Keleher, C.A., C. Goutte, and A.D. Johnson. 1988. The yeast cell-type-specific repressor $\alpha 2$ acts cooperatively with a noncell-type-specific protein. Cell 53: 927--936.

Komachi, K., M.J. Redd, and A.D. Johnson. 1994. The WD repeats of Tupl interact with the homeo domain protein $\alpha 2$. Genes \& Dev. 8: 2857-2867.

Konig, H., H. Ponta, H.J. Rahmsdorf, and P. Herrlich. 1992. Interference between pathway-specific transcription factors: Glucocorticoids antagonize phorbol ester-induced AP-1 activity without altering AP-1 site occupation in vivo. $E M B O$ I. 11: 2241-2246.

Kunkel, T.A. 1985. Rapid and efficient site-specific mutagenesis without phenotypic selection. Proc. Natl. Acad. Sci. 82: 488-492.

Kurokawa, R., M. Soderstrom, A. Horlein, S. Halachmi, M. Brown, M.G. Rosenfeld, and C.K. Glass. 1995. Polarity-specific activities of retinoic acid receptors determined by a co-repressor. Nature 377: 451-454.

Lefstin, J.A., J.R. Thomas, and K.R. Yamamoto. 1994. Influence of a steroid receptor DNA-binding domain on transcriptional regulatory functions. Genes \& Dev. 8: 2842-2856.

Leung, D.W., E. Chen, and D.V. Goeddel. 1989. A method for random mutagenesis of a defined DNA segment using a modified polymerase chain reaction. Technique 1: 11-15.

Lucibello, F.C., E.P. Slater, K.U. Jooss, M. Beato, and R. Muller. 1990. Mutual transrepression of fos and the glucocorticoid receptor: Involvement of a functional domain in fos which is absent in fosB. EMBO /. 9: 2827-2834.

Luisi, B.F., W.X. Xu, Z. Otwinowski, L.P. Freedman, K.R. Yamamoto, and P.B. Sigler. 1991. Crystallographic analysis of 
the interaction of the glucocorticoid receptor and DNA. $\mathrm{Na}$ ture 352: 497-505.

McKnight, S.L. and R. Kingsbury. 1982. Transcriptional control signals of a eukaryotic protein-coding gene. Science 217: 316-324.

Meyer, B.J., R. Mauer, and M. Ptashne. 1980. $\lambda$ repressor directly activates gene transcription. J. Mol. Biol. 139: 195-205.

Miller, J., A.D. McLachlan, and A. Klug. 1985. Repetitive zincbinding domains in the protein transcription factor IIIA from Xenopus oocytes. EMBO I. 4: 1609-1614.

Miner, J.N., M.I. Diamond, and K.R. Yamamoto. 1991. Joints in the regulatory lattice: Composite regulation by steroid receptor-APl complexes. Cell Growth Differ. 2: 525-530.

Mittal, R., K.U. Kumar, A. Pater, and M.M. Pater. 1994. Differential regulation by c-jun and c-fos protooncogenes of hormone response from composite glucocorticoid response element in human papilloma virus type 16 regulatory region. Mol. Endocrinol. 8: 1701-1708.

Mordacq, J.C. and D.I.H. Linzer. 1989. Co-localization of elements required for phorbol ester stimulation and glucocorticoid repression of proliferin gene expression. Genes \& Dev. 3: 760-769.

Niu, W., Y. Zhou, Q. Dong, Y.W. Ebright, and R.H. Ebright. 1994. Characterization of the activating region of Escherichia coli catabolite gene activator protein (CAP). I. Saturation and alanine-scanning mutagenesis. I. Mol. Biol. 243: 595602.

Orth, D.N., W.J. Kovacs, and C.R. Debold. 1992. Williams textbook of endocrinology (ed. J.D. Wilson and D.W. Foster). Saunders, Philadelphia, PA.

Pearce, D. and K.R. Yamamoto. 1993. Mineralocorticoid and glucocorticoid receptor activities distinguished by nonreceptor factors at a composite response element. Science 259: 1161-1165.

Pedersen, H., L. Sogaard-Andersen, B. Holst, and P. ValentinHansen. 1991. Heterologous cooperativity in Escherichia coli. The CytR repressor both contacts DNA and the cAMP receptor protein when binding to the deoP2 promoter. I. Biol. Chem. 266: 17804-17808.

Picard, D. and K.R. Yamamoto. 1987. Two signals mediate hormone-dependent nuclear localization of the glucocorticoid receptor. EMBO I. 6: 3333-3340.

Pignoni, F., R.M. Baldarelli, E. Steingrimsson, R.J. Diaz, A. Patapoutian, J.R. Merriam, and J.A. Lengyel. 1990. The Drosophila gene tailless is expressed at the embryonic termini and is a member of the steroid receptor superfamily. Cell 62: 151-163.

Pratt, W.B., D.J. Jolly, D.V. Pratt, S.M. Hollenberg, V. Giguere, F.M. Cadepond, G. Schweizer-Groyer, M.-G. Catelli, R.M. Evans, and E.-E. Baulieu. 1988. A region in the steroid binding domain determines the formation of the non-DNA binding, $9 \mathrm{~S}$ glucocorticoid receptor complex. J. Biol. Chem. 263: 267-273.

Ray, A., K.S. LaForge, and P.B. Sehgal. 1991. Repressor to activator switch by mutations in the first $\mathrm{Zn}$ finger of the glucocorticoid receptor: Is direct binding necessary? Proc. Natl. Acad. Sci. 88: 7086-7090.

Ray, A. and K.E. Prefontaine. 1994. Physical association and functional antagonism between the $\mathrm{p} 65$ subunit of transcription factor NF-kappa B and the glucocorticoid receptor. Proc. Natl. Acad. Sci. 91: 752-756.

Rusconi, S. and K.R. Yamamoto. 1987. Functional dissection of the hormone and DNA binding activities of the glucocorticoid receptor. EMBO I. 6: 1309-1315.

Saatcioglu, F., F.-X. Claret, and M. Karin. 1994. Negative transcriptional regulation by nuclear receptors. Semin. Cancer
Biol. 5: 347-359.

Scheinman, R.I., A. Gualberto, C.M. Jewell, J.A. Cidlowski, and A.S. Baldwin. 1995. Characterization of mechanisms involved in transrepression of NF-kappa B by activated glucocorticoid receptors. Mol. Cell. Biol. 15: 943-953.

Schena, M. and K.R. Yamamoto. 1988. Mammalian glucocorticoid receptor derivatives enhance transcription in yeast. Science 241: 965-967.

Schule, R., P. Rangarajan, S. Kliewer, L.J. Ransone, J. Bolado, N. Yang, I.M. Verma, and R.M. Evans. 1990. Functional antagonism between oncoprotein c-Jun and the glucocorticoid receptor. Cell 62: 1217-1226.

Schule, R., P. Rangarajan, N. Yang, S. Kliewer, L.J. Ransone, J. Bolado, I.M. Verma, and R.M. Evans. 1991. Retinoic acid is a negative regulator of AP-1-responsive genes. Proc. Natl. Acad. Sci. 88: 6092-6096.

Sheldon, M. and D. Reinberg. 1995. Transcriptional activation. Tuning-up transcription. Curr. Biol. 5: 43-46.

Sleigh, M.J. 1986. A nonchromatographic assay for expression of the chloramphenicol acetyltransferase gene in eucaryotic cells. Anal. Biochem. 156: 251-256.

Tan, S. and T.J. Richmond. 1990. DNA binding-induced conformational change of the yeast transcriptional activator PRTF. Cell 62: 367-377.

Tijan, R. and T. Maniatis. 1994. Transcriptional activation: A complex puzzle with few easy pieces. Cell 77: 5-8.

Tsai, M.-J. and B.W. O'Malley. 1994. Molecular mechanisms of action of steroid/thyroid receptor superfamily members. Annu. Rev. Biochem. 63: 45l-486.

Tsai, S.Y., J. Carlstedt-Duke, N.L. Weigel, K. Dahlman, J.A. Gustafsson, M.-I. Tsai, and B.W. O'Malley. 1988. Molecular interactions of steroid hormone receptor with its enhancer element: Evidence for receptor dimer formation. Cell 63: 361-369.

Vivanco, M.d.M., R. Johnson, P.E. Galante, D. Hanahan, and K.R. Yamamoto. 1995. A transition in transcription activation by the glucocorticoid and retinoic acid receptors at the tumor stage of dermal fibrosarcoma development. EMBO $\%$. 14: 2217-2228.

Vivanco-Ruiz, M.d.M., T. Bugge, P. Hirschmann, and H.G. Stunnenberg. 1991. Functional characterization of a natural retinoic acid receptor. $E M B O$ I. 10: 3829-3838.

Wu, A., J.A. Wemmie, N.P. Edgington, M. Goebel, J.L. Guevara, and W.S. Moye-Rowley. 1993. Yeast bZIP proteins mediate pleiotropic drug and metal resistance. I. Biol. Chem. 268: $18850-18858$.

Yamamoto, K.R., D. Pearce, J.R. Thomas, and J.N. Miner. 1993. Combinatorial regulation at a mammalian composite element. In Transcriptional regulation (ed. S.L. McKnight and K.R. Yamamotol, pp. 3-32. Cold Spring Harbor Laboratory Press, Cold Spring Harbor, NY.

Yang-Yen, H.-F., J.-C. Chambard, Y.-L. Sun, T. Smeal, T.J. Schmidt, J. Drouin, and M. Karin. 1990. Transcriptional interference between c-jun and the glucocorticoid receptor: Mutual inhibition of DNA binding due to direct proteinprotein interaction. Cell 62: 1205-1215.

Yang-Yen, H.-F., X.K. Zhang, G. Graupner, M. Tzukerman, B. Sakamoto, M. Karin, and M. Pfahl. 1991. Antagonism between retinoic acid receptors and AP-1: Implications for tumor promotion and inflammation. New Biol. 3: 1206-1219.

Yu, R.T., M. McKeown, R.M. Evans, and K. Umesono. 1994. Relationship between Drosophila gap gene tailless and a vertebrate nuclear receptor Tlx. Nature 370: 375-379. 


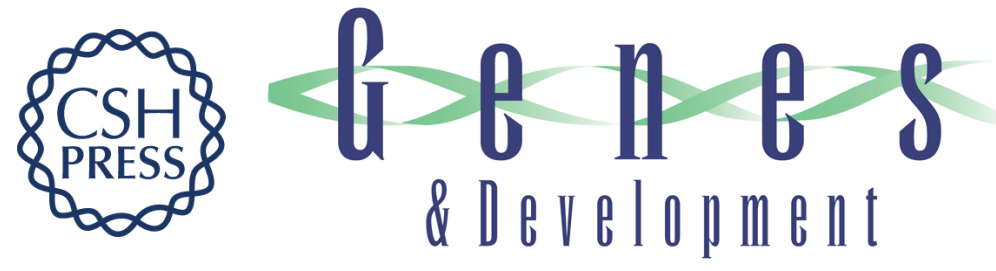

\section{Intracellular receptors use a common mechanism to interpret signaling information at response elements.}

D B Starr, W Matsui, J R Thomas, et al.

Genes Dev. 1996, 10:

Access the most recent version at doi:10.1101/gad.10.10.1271

References This article cites 71 articles, 28 of which can be accessed free at:

http://genesdev.cshlp.org/content/10/10/1271.full.html\#ref-list-1

License

Email Alerting

Service

Receive free email alerts when new articles cite this article - sign up in the box at the top right corner of the article or click here.

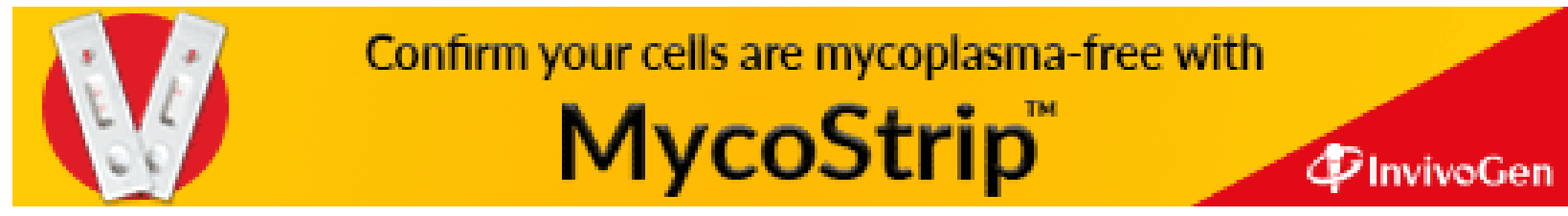

